\title{
Comparative study of the different degrees of risk of gastrointestinal stromal tumor
}

\section{Estudo comparativo dos diferentes graus de risco no tumor estromal gastrointestinal}

Rodrigo Panno Basilio de Oliveira'; Pedro Eder Portari Filho, tCBC-RJ2; Antonio Carlos Iglesias, tCBC-RJ3; Carlos Alberto Basilio de Oliveira, TcCBC-RJ4; Vera lucia Nunes Pannain ${ }^{5}$

\section{A}

\begin{abstract}
Objective: To evaluate the applicability of the main categories of risk and morphological factors in the prognosis of gastrointestinal stromal tumors. Methods: we retrospectively studied fifty-four cases of GIST, assessing the main prognostic factors of this neoplasis: risk levels, topography, size, mitotic index, necrosis, histological subtype and immunophenotype. We also verified their association and the reduction of overall survival. Results: Univariate analysis showed that tumors with mitoses number greater than 5 per $50 C G A$ (high-power fields), the presence of necrosis and a high risk for both the systems proposed by Fletcher and Miettinen had a significant association with reduced survival $(p=0.00001,0.0056,0.03$ and 0.009 , respectively). The remaining analyzed factors (size, histological subtype, topography and immunophenotype) had no such association. Multivariate analysis (Jacard index) showed that the Miettinen degree of risk was the one that best correlated with prognosis. Conclusion: the risk criteria of Fletcher and Miettinen are important in assessing the prognosis of patients with gastrointestinal stromal tumors, especially the latter, which adds to the mitotic index and the presence of tumor necrosis.
\end{abstract}

Key words: Gastrointestinal Stromal Tumors. Risk Factors. Digestive System Neoplasms. Prognosis. Mitotic Index.

\section{INTRODUCTION}

G astrointestinal stromal tumors (GIST) are the most common mesenchymal neoplasms of the gastrointestinal tract ${ }^{1}$, their incidence being estimated at 14 to 20 cases per million population ${ }^{2}$; they are more frequent in male patients older than 50 years old ${ }^{3}$. The pathogenesis is related to mutational changes in two tyrosine kinase receptors: KIT and PDGFR-alpha (plateletderived growth factor receptor alpha) on the surface of the interstitial cells of Cajal, the former being the most common ( $85 \%$ of cases) ${ }^{4,5}$. Gastrointestinal stromal tumors can develop in any topography, from the esophagus to the rectum. However, they are more common in the stomach (50\% to 60\%), followed by small intestine (20\% to $30 \%$ ), colon $(10 \%)$, rectum or esophagus $(5 \%)^{6}$. Macroscopically, the tumor lesions often have a nodular form, transmural involvement and submucosal growth, with ulceration of the mucosa or not. In light microscopy, histology reveals three types: the most common spindle (70\%), epidermoid (20\%) and the mixed type (10\%), when there is combination of epithelioid and spindle ones? ${ }^{7}$.

The diagnosis of stromal neoplasms is based on immunohistochemical study with CD117 marker, expressed in most such neoplasias ${ }^{1}$. Noteworthy are also other markers: DOG 1, nestin, theta protein kinase $C$ and carbonic anhydrase $\|^{8}$. The differential diagnosis includes: desmoid tumor, inflammatory myofibroblastomas, leiomyoma, inflammatory fibroid polyp, neuroma, neurossarcoma, sarcomatoid mesothelioma and metastatic melanoma ${ }^{7,9,10}$

GIST prognosis is still matter of discussion. Currently there are different classifications ${ }^{7,11-15}$ aimed to stratify tumors into groups, linking them to a higher or lower risk of tumor recurrence and/or distant metastasis ${ }^{8,12}$. Of all the classifications mentioned above, the two most commonly used are the one of Fletcher et al. ${ }^{7}$ and Miettinenet al.. ${ }^{11}$. The first classification established two factors as prognostic parameters, one macroscopic and the other microscopic. This combination resulted in a system that ranked the stromal tumors in different degrees of risk. The second,

\footnotetext{
1. Department of Pathology and Clinical Support, School of Medicine and Surgery, Universidade Federal do Estado do Rio de Janeiro - UNIRIO, Rio de Janeiro State, Brazil; 2. Department of General and Specialized Surgery, School of Medicine and Surgery, UNIRIO, Rio de Janeiro State, Brazil; 3. Hospital Universitário Gaffrée-Guinle, UNIRIO, Rio de Janeiro State, Brazil; 4. Department of Pathology, Pontifícia Universidade Católica do Rio de Janeiro - PUC/RJ, Rio de Janeiro State, Brazil; 5. Department of Pathology, Faculty of Medicine, Universidade Federal do Rio de Janeiro - UFRJ, Rio de Janeiro State, Brazil.
} 
based on a larger number of cases, whose diagnosis was supported both by immunohistochemical and genetic studies, and especially with a prolonged follow-up. In addition to the criteria used in Fletcher et al..$^{7}$ classification, a third was added to Miettinen et al. ${ }^{11}$ classification, the location of the tumor, allowing greater stratification of risk groups and the establishment of a percentage related to the chances of development of recurrence and / or metastasis.

The aim of this study was to evaluate the applicability of the main risk categories (Fletcher and Miettinen) and morphological factors in the prognosis of gastrointestinal stromal tumor.

\section{METHODS}

We retrospectively studied a cohort of 54 cases of gastrointestinal stromal tumors with positive immunohistochemistry for the expression of anti-CD117 antibody, completely excised with no evidence of disseminated disease and not associated with other malignancies. These came from the files of the Pathology Services of the Hospital Univeristário Gaffrée e Guinle (HUGG/UNIRIO) and Hospital Univeristário Clementino Fraga Filho (HUCFF/UFRJ). We obtained data on age, gender and clinical outcomes of patients from medical records and requests from pathological examinations. The study evaluated the data of patients alive and without recurrence, of patients who died from the disease, and of live patients with recurrent disease. Thetime with disease evolution was counted from the date of surgery until the last contact of the patient, recorded in the medical record. The project was approved by the Ethics in Research Committee of HUCFF under number 079/05.

\section{Morphological data and risk degrees}

The topography and tumor size were obtained from requests from pathological examinations. The mitotic index was assessed in 50CGA (high-power fields), using an Olympus BX40 microscope with a 40X objective and 10x eyepiece ${ }^{7}$. The mitotic count was performed by two pathologists. The histological subtype was determined by the predominant presentation form at microscopy (spindle, epithelioid, mixed); the presence of necrosis was evaluated in areas distant from those corresponding to the ulceration of the overlying mucosa, when present ${ }^{7}$. When assessing degrees of risk, we employed the ones proposed by Fletcher et al. ${ }^{7}$ (Table 1) and Miettinen et al. ${ }^{11}$ (Table 2).

\section{Immunohistochemistry}

The following antibodies were used: anti-CD117 (Dako, Carpinteria, California / USA) diluted 1:100; antiprotein S-100 (Dako, Carpenteria, California / USA) diluted 1:1,000; and anti-smooth muscle actin (Dako, Carpinteria, California / USA) diluted 1: 250. Subsequently, sections were incubated with Universal LSAB ${ }^{\mathrm{TM}} 2 \mathrm{kit} / \mathrm{HRP}$ Rabbit / Mouse - K0675 (Dako, Carpinteria, California / USA). The positivity for anti-protein S-100 antibody and muscle-specific anti-actin defined the immunophenotype of neoplasms,

Table 1 - $\quad$ Fletcher risk degrees.

\begin{tabular}{lll}
\hline Risk degree & Macroscopic size $(\mathrm{cm})$ & Mitotic index $(50$ CGA) \\
\hline Very low & $<2$ & $<5$ \\
Low & $2-5$ & $<5$ \\
Intermediary & $<5 \quad 5-10$ & $6-10 \quad<5$ \\
High & $>5>10$ any size & $>5$ any index $>10$ \\
\hline
\end{tabular}

Fletcher et al. ${ }^{7}$

Table 2 - Mettinen Risk Degrees.

\begin{tabular}{|c|c|c|c|c|c|}
\hline \multirow{2}{*}{$\begin{array}{l}\text { Tumor parameters } \\
\text { Index Mitotic }\end{array}$} & \multicolumn{5}{|c|}{ Risk of disease progression } \\
\hline & Size & Stomach & Duodenum & Ileum/ jejunum & Rectum \\
\hline \multirow[t]{4}{*}{$<5$ per50CGA } & $<2 \mathrm{~cm}$ & $\mathrm{No}(0)$ & None (0) & $\mathrm{No}(0)$ & $\mathrm{No}(0)$ \\
\hline & $2>$ to $<5 \mathrm{~cm}$ & Very low (1.9 percent) & $\operatorname{Low}(4.3 \%)$ and & Low(8.3 percent) & Low(8.5 percent) \\
\hline & $5>$ to $<10 \mathrm{~cm}$ & Low(3.6 percent) & Moderate(24) & Datainsufficient & Datalnsufficient \\
\hline & $>10 \mathrm{~cm}$ & Moderate(10\% off) & $\operatorname{High}(52 \%$ off) & High(34\% off) & $\operatorname{High}(57)$ \\
\hline \multirow[t]{4}{*}{$>5$ per50 CGA } & $<2 \mathrm{~cm}$ & None $(0)$ & High(61) & Datainsufficient & $\operatorname{High}(54 \%$ off) \\
\hline & $2>$ to $<5 \mathrm{~cm}$ & Moderate(16\% off) & $\operatorname{High}(73)$ & High(50\% off) & $\operatorname{High}(52 \%$ off $)$ \\
\hline & $5>$ to $<10 \mathrm{~cm}$ & High(55\% off) & High(85 percent) & Datainsufficient & Datalnsufficient \\
\hline & $>10 \mathrm{~cm}$ & $\operatorname{High}(86)$ & High(90 percent) & High(86) & $\operatorname{High}(71)$ \\
\hline
\end{tabular}

Miettinen et al. ${ }^{11}$ 


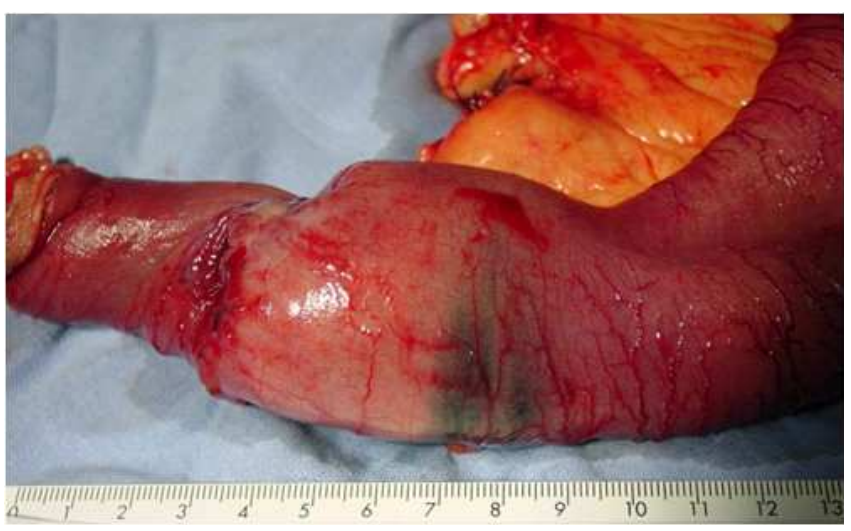

Figure 1 - Gastrointestinal stromal tumor of the jejunum, with serosal bulging.

classifying them respectively as muscular, neural, double or null (no expression) ${ }^{7}$.

\section{Statistical analysis}

All factors were submitted to analysis of the direct and univariate frequencies with the chi-square test. The statistical significance was set at $p<0.05$. The criteria that showed statistical significance in the univariate analysis were submitted to the Jaccard similarity index.

\section{RESULTS}

The study group consisted of 54 patients, 30 (59.5\%) of them women and 24 , men (40.5\%) with a mean age of $57.34 \pm 13.71$, ranging from 24 to 83 . Regarding the topography of neoplasms, tumors were located: one $(1.8 \%)$ in the esophagus, $27(50 \%)$ in the stomach, 20 $(37.1 \%)$ in the small intestine (Figure 1) and six (11.1\%) in the large intestine.

The size of the tumors ranged from 2.0 to 33 $\mathrm{cm}$ (median 8) with 12 measuring up to $5 \mathrm{~cm}$ (included) along the longest axis (22.3\%) and 42 were greater than $5 \mathrm{~cm}(77.7 \%)$. As for the mitotic index, 36 cases had less than five mitosis per 50 CGA (66.8\%) and the others (18), more than five (33.2\%). The histological subtype of 32 tumors $(59.3 \%)$ were spindle, of nine $(16.6 \%)$, epithelioidand of $13,(24.1 \%)$ mixed. Necrosis was absent in 33 cases $(61.2 \%)$ and present in $21(38.8 \%)$. The immunophenotype was as follows: $26(48.1 \%)$ tumors showed muscle differentiation, 11 (20.4\%) neural, seven $(13.3 \%)$, double differentiation (nerve and muscle) and $10(18.2 \%)$, none.

Regarding the degree of risk, according to Fletcher et al. ${ }^{7}$ tumors were thus classified: Ten $(18.6 \%)$ of lowrisk, 17 (31.4\%) of intermediate risk, 27 (50\%) of high-risk and none of very low risk; and according to Miettinen et al. ${ }^{11}$, three $(5.4 \%)$ had no risk, four $(7.4 \%)$ of very low risk, ten $(18.6 \%)$ of low-risk, 14 (26\%) of intermediate risk and $23(42.6 \%)$ of high risk.
As for the status of the patients, 33(61.2\%) were alive without disease (good prognosis) and 21 (38.8\%), alive with disease and / or died due to the neoplasia, and the follow-up period ranged from one to 248 months, with a median of 53 months. Among the parameters studied and tested in the univariate analysis, those who showed an adverse effect on overall survival was the mitoses number greater than five mitosis per 50 CGA $(p=0.00001)$. In multivariate analysis, employing the Jaccard Index, we found that the Miettinen degree of risk showed better association with reduced overall survival.

\section{DISCUSSION}

The characterization of the biological behavior of GIST is essential for signaling of patients who are outpatients, those who have the indication of treatment with imatinibmesylate. In this series, the gender distribution was different from the ones in the literature, there was a predominance of females (59.5\%), while literature indicates a homogeneous distribution or a slight predominance of males ${ }^{11,16-18}$ and, by contrast, the average age of patients (57 years) was similar to that found in other series 2,17 .

In this sample, the preferred location in the stomach, followed by small intestine, large intestine and esophagus was also observed by other authors ${ }^{2,11}$. Although we found no statistically significant difference between the different organs involved $(p=0.08)$, some studies ${ }^{11,19,20}$ have shown that the GIST location directly influences the prognosis and those located in the stomach had more favorable course than those found in other topographies. Statistically, we found that the colonic topography directly influenced prognosis, since five out ofthe six tumors had unfavorable follow-up (metastasis/death), which was also found in another study3.

The importance of tumor size in GIST prognosis has undergone major changes since the publication of Miettinen et al. ${ }^{11}$, and came to corroborate evidence that linked the neoplastic diameter with tumor topography, ie, gastric tumors showed worse prognosis when their size was greater than $10 \mathrm{~cm}$, while cancer of the small intestine showed poor prognosis when greater than $5 \mathrm{~cm}^{19,20}$. However, in general, gastrointestinal stromal tumors with more than five centimeters are related to a worse prognosis. In this series there was no demonstration of prognosis associated with tumor size, a fact possibly influenced by the number of cases. Independently of this demonstration, some data needs to be emphasized, because the average size of the tumors of patients with worse prognosis was higher than in patients with good prognosis. Also, of the 21 tumors with recurrence, 17 were larger than $5 \mathrm{~cm}$, from which it can be inferred that size is an important prognostic criteria.

The mitotic index (MI) of more than 5 per 50 CGA was also a variable associated with prognosis, as observed 
by other authors $7,11,15,17,18,20$. The evaluation of this variable is present in the two main risk levels ${ }^{7,11}$ used to characterize GIST prognosis. The risk degree of Fletcher et al. ${ }^{7}$, has three MI subdivisions ( $<5,6-10$ and $>5$ ), while for Miettinen et al. ${ }^{11}$, there is a binary division ( $<5$ and $>5$ ). These forms of division diminish the discriminatory power ofMl, a fact described after analysis of 929 tumors and observation of differences in patient survival when the stratification was done in four segments $(<5,5-10,10-30 \text { and }>30)^{21}$. In addition, the correct interpretation of true mitosis is another problem since the material fixation time may impair its identification ${ }^{18}$.

The histological subtype in our study was not related to patients' prognosis. However, it is noteworthy that among the 12 epithelioid and mixed neoplasms, ten had unfavorable follow-up. The poor survival of patients with tumors of the mixed or epithelioid patterns has also been reported, but this finding only held for the mixed pattern in multivariate analysis ${ }^{22,23}$. Another study suggests that the spindle histological pattern is associated with longer patients survival ${ }^{20}$. In view of these conflicting results, we believe that this point still needs further study.

The presence of necrosis was associated with poor prognosis, which was also found in other studies ${ }^{18,20}$. It is believed that necrosis is directly related to severe proliferative activity of the tumor, ie, the most aggressive would present necrosis areas.

As for the studied immunohistochemical markers, there was no correlation of the neoplasia immunophenotype with patients' prognosis, as evidenced in another series ${ }^{2}$ Nonetheless, neoplasms with muscle differentiation showed greater disease-free intervals ${ }^{17}$. However, the authors point out that these results need to be evaluated carefully, since the tumors with muscle differentiation had a less aggressive biological course.

Regarding the two GIST prognostic characterization systems, there was evidence of association with prognosis in both Fletcher et al. ${ }^{7}$ and Miettinen et al. ${ }^{11}$ classification, which was also found by other authors ${ }^{14,18,24,25}$.
However, in this series we found a better risk statistical correlation with the Miettinen et al. ${ }^{11}$ classification. This can be explained by the introduction of a third criterion (location), the study of more than 2,000 cases, with long follow-up of patients and mainly the greater stratification of the risk categories, allowing a reclassification of the neoplasias ${ }^{25}$. This can be observed in our study, with the appearance of three tumors with no risk, four tumors with very low risk, and also reduction in both neoplasias at intermediate risk (from 17 to 14) and high risk (from 27 to 23).

Although the relationship between prognosis and the two classifications, there are still tumors that do not follow this natural history, ie there are neoplasms classified as low risk that progress to metastasis / death, and other categorized as high risk, whose patients present favorable follow-up (alive without recurrence) ${ }^{7}$. The foregoing can be explained due to various conflicting situations in the two proposed systems. Fletcher et al. ${ }^{7}$ fails to point out the mitosis counting method, the size measuring mode, the definition of what is a high-power field, and also does not define the risk degree to neoplasias with exactly five mitosis per $50 \mathrm{CGA}^{25}$. In Miettinen et al. ${ }^{11}$, certain subgroups have few documented neoplasias, such as duodenal tumors less than $2 \mathrm{~cm}$ and lesions with mitotic index greater than five per 50 CGA, which prevents their categorization ${ }^{8}$. In addition, there is no classification for GIST in the esophagus or colon, whose biological behavior can be misinterpreted ${ }^{25}$.

We conclude that both the systems proposed by Fletcher et al. ${ }^{7}$ and Mettinnenet al. ${ }^{11}$ in cases of GIST showed correlation with prognosis, although in this series the latter has proved to be superior. However, we understand that such systems need to be reviewed, either through a new form of the current division criteria (number of mitosis per CGA and tumor size) or by including other morphological variables, such as necrosis and less frequent location sites. However, we understand that we still need more studies involving more cases, especially in those places where GISTs are less common.

\title{
R E S U M O
}

\begin{abstract}
Objetivo: avaliar a aplicabilidade das principais categorias de risco e de fatores morfológicos no prognóstico tumor estromal gastrointestinal. Métodos: cinquenta e quatro casos de GIST foram estudados retrospectivamente considerando-se os principais fatores prognósticos da neoplasia: graus de risco, topografia, tamanho, índice mitótico, necrose, subtipo histológico e imunofenótipo. Foi também verificada a sua associação e a redução da sobrevida global dos pacientes. Resultados: a análise univariada mostrou que os tumores com número de mitoses maior que 5/50CGA (campos de grande aumento), a presença de necrose, de alto risco tanto para os sistemas propostos por Fletcher, quanto para Miettinen tiveram associação significativa com redução da sobrevida $(p=0,00001,0,0056,0,03$ e 0,009, respectivamente). Enquanto que os demais fatores analisados (tamanho, subtipo histológico, topografia e imunofenótipo) não tiveram tal associação. A análise multivariada (índice de Jacard) demonstrou que o grau de risco de Miettinen foi aquele que melhor se relacionou com o prognóstico. Conclusão: os critérios de risco de Fletcher e de Miettinen são importantes na avaliação do prognóstico de pacientes com tumor estromal gastrointestinal, principalmente este último, que se soma ao índice mitótico e a necrose tumoral.
\end{abstract}

Descritores: Tumores do Estroma Gastrointestinal; Fatores de Risco; Neoplasias do Sistema Digestório. Prognóstico. Índice Mitótico. 


\section{REFERENCES}

1. Miettinen M, Lasota J. Histopathology of gastrointestinal stromal tumor. J Surg Oncol. 2011;104(8):865-73.

2. Nilsson $B$, Bümming $P$, Meis-Kindblom JM, Odén $A$, Dortok $A$, Gustavsson B, et al. Gastrointestinal stromal tumors: the incidence,prevalence, clinical course, and prognostication in the preimatinibmesylate era-a population-based study in western Sweden. Cancer.2005;103(4):821-9.

3. Gold JS, van der Zwan SM, Gönen M, Maki RG, Singer S, Brennan $M F$, et al. Outcome of metastatic GIST in the era before tyrosine kinase inhibitors. Ann Surg Oncol. 2007;14(1):134-42. Erratum in: Ann Surg Oncol. 2007:14(10):3027.

4. Kitamura Y, Hirota S, Nishida T. Gastrointestinal stromal tumors (GIST): a model for molecule-based diagnosis and treatment of solid tumors. Cancer Sci. 2003;94(4):315-20. Erratum in: Cancer Sci. 2003;94(10):930

5. Rubin BP. Gastrointestinal stromal tumours: an update. Histopathology. 2006;48(1):83-96.

6. Tran T, Davila JA, El-Serag HB. The epidemiology of malignant gastrointestinal stromal tumors:an analysis of 1,458 cases from 1992 to 2000. Am J Gastroenterol. 2005;100(1):162-8.

7. Fletcher CD, Berman JJ, Corless C, Gorstein F, Lasota J, Longley BJ, et al. Diagnosis of gastrointestinal stromal tumors: A consensus approach. Hum Pathol. 2002;33(5):459-65.

8. Wong NA. Gastrointestinal stromal tumours - an update for histopathologists. Histopathology. 2011;59(5):807-21.

9. Shidham VB, Chivukula M, Gupta D, Rao RN, Komorowski R. Immunohistochemical comparison of gastrointestinal stromal tumor and solitary fibrous tumor. Arch Pathol Lab Med. 2002;126(10):1189-92.

10. Plaat BE, Hollema H, Molenaar WM, Torn Broers GH, Pijpe J, Mastik MF, et al. Soft tissue leiomyosarcomas and malignant gastrointestinal stromal tumors: differences in clinical outcome and expression of multidrug resistance proteins. J Clin Oncol. 2000;18(18):3211-20.

11. Miettinen M, Lasota J. Gastrointestinal stromal tumors: review on morphology, molecular pathology, prognosis, and differential diagnosis. Arch Pathol Lab Med. 2006;130(10):1466-78.

12. Joensuu $H$, Vehtari $A$, Riihimäki J, Nishida $T$, Steigen $S E$, Brabec $P$, et al. Risk of recurrence of gastrointestinal stromal tumour after surgery: an analysis of pooled population-based cohorts. Lancet Oncol. 2012;13(3):265-74.

13. Huang $H$, Liu $Y X$, Zhan ZL, Liang $H$, Wang $P$, Ren XB. Different sites and prognoses of gastrointestinal stromal tumors of the stomach: report of 187 cases. World J Surg. 2010;34(7):1523-33.

14. Goh BK, Chow PK, Yap WM, Kesavan SM, Song IC, Paul PG, et al. Which is the optimal risk stratification system for surgically treated localized primary GIST? Comparison of three contemporary prognostic criteria in 171 tumors and a proposal for a modified Armed Forces Institute of Pathology risk criteria. Ann Surg Oncol. 2008;15(8):2153-63.

15. Joensuu H. Risk stratification of patients diagnosed with gastrointestinal stromal tumor. Hum Pathol. 2008;39(10):1411-9.

16. Nakamura N, Yamamoto H, Yao T, Oda Y, Nishiyama K, Imamura $M$, et al. Prognostic significance of expressions of cell-cycle regulatory proteins in gastrointestinal stromal tumor and the relevance of the risk grade. Hum Pathol. 2005;36(7):828-37.

17. Belev B, Brèiæ I, Prejac J, Golubiæ ZA, Vrbanec D, Bo•ikov J, et al. Role of $\mathrm{Ki}-67$ as a prognostic factor in gastrointestinal stromal tumors. World J Gastroenterol. 2013;19(4):523-7.

18. Artigiani Neto R, Logullo AF, Stávale JN, Lourenço LG. Ki-67 expression score correlates to survival rate in gastrointestinal stromal tumors (GIST). Acta Cir Bras. 2012;27(5):315-21.

19. Cao $H$, Zhang $Y$, Wang $M$, Shen DP, Sheng ZY, Ni XZ, et al. Prognostic analysis of patients with gastrointestinal stromal tumors: a single unit experience with surgical treatment of primary disease. Chin Med J. 2010:123(2):131-6.

20. Hou YY, Lu SH, Zhou Y, Qi WD, Shi Y, Tan YS,et al. Stage and histological grade of gastrointestinal stromal tumors based on a new approach are strongly associated with clinical behaviors. Mod Pathol. 2009;22(4):556-69.

21. Dei Tos AP, Wagner AJ, Modena P, Comandone A, Leyvraz S. Epithelioid soft tissue tumors. Semin Oncol. 2009;36(4):347-57.

22. Singer $S$, Rubin $B P$, Lux ML, Chen $C J$, Demetri GD, Fletcher $C D$, et al.Prognostic value of KIT mutation type, mitotic activity, and histologic subtype in gastrointestinal stromal tumors. J ClinOncol.2002;20(18):3898-905.

23. Koay MH, Goh YW, lacopetta B, Grieu F, Segal A, Sterrett GF, et al. Gastrointestinal stromal tumours (GISTs): a clinicopathological and molecular study of 66 cases. Pathology. 2005;37(1):22-31.

24. Eisenberg BL, Pipas JM. Gastrointestinal stromal tumorbackground, pathology, treatment. Hematol Oncol Clin North Am. 2012;26(6):1239-59.

25. Patel $\mathrm{S}$. Navigating risk stratification systems for the management of patients with GIST. Ann Surg Oncol. 2011;18(6):1698-704.

Received 15/02/2014

Accepted for publication 18/04/2014

Conflict of interest: none

Source of funding: none

Address for correspondence:

Carlos Alberto Basilio de Oliveira

E-mail: basiliopatologia@br.inter.net 